\title{
Pre-eclampsia Diagnosis and Treatment Options: A Review of Published Economic Assessments
}

\author{
Neily Zakiyah ${ }^{1} \cdot$ Maarten J. Postma $^{1,2} \cdot$ Philip N. Baker $^{3}$ • \\ Antoinette D. I. van Asselt ${ }^{1,2}$ On behalf of the IMPROvED Consortium
}

Published online: 6 June 2015

(c) The Author(s) 2015. This article is published with open access at Springerlink.com

\begin{abstract}
Background Pre-eclampsia is a pregnancy complication affecting both mother and fetus. Although there is no proven effective method to prevent pre-eclampsia, early identification of women at risk of pre-eclampsia could enhance appropriate application of antenatal care, management and treatment. Very little is known about the cost effectiveness of these and other tests for pre-eclampsia, mainly because there is no clear treatment path. The aim of this study was to provide a comprehensive overview of the existing evidence on the health economics of screening, diagnosis and treatment options in pre-eclampsia.

Methods We searched three electronic databases (PubMed, EMBASE and the Cochrane Library) for studies on screening, diagnosis, treatment or prevention of preeclampsia, published between 1994 and 2014. Only full papers written in English containing complete economic assessments in pre-eclampsia were included.
\end{abstract}

Electronic supplementary material The online version of this article (doi:10.1007/s40273-015-0291-x) contains supplementary material, which is available to authorized users.

Antoinette D. I. van Asselt

a.d.i.van.asselt@umcg.nl

1 Unit of PharmacoEpidemiology and PharmacoEconomics, Department of Pharmacy, University of Groningen,

A. Deusinglaan 1, 9713 AV Groningen, The Netherlands

2 Health Technology Assessment Unit, Department of Epidemiology, University Medical Center Groningen, Groningen, The Netherlands

3 Institute of Science and Technology in Medicine, Keele University, Staffordshire, UK
Results From an initial total of 138 references, six papers fulfilled the inclusion criteria. Three studies were on the cost effectiveness of treatment of pre-eclampsia, two of which evaluated magnesium sulphate for prevention of seizures and the third evaluated the cost effectiveness of induction of labour versus expectant monitoring. The other three studies were aimed at screening and diagnosis, in combination with subsequent preventive measures. The two studies on magnesium sulphate were equivocal on the cost effectiveness in non-severe cases, and the other study suggested that induction of labour in term pre-eclampsia was more cost effective than expectant monitoring. The screening studies were quite diverse in their objectives as well as in their conclusions. One study concluded that screening is probably not worthwhile, while two other studies stated that in certain scenarios it may be cost effective to screen all pregnant women and prophylactically treat those who are found to be at high risk of developing pre-eclampsia.

Discussion This study is the first to provide a comprehensive overview on the economic aspects of preeclampsia in its broadest sense, ranging from screening to treatment options. The main limitation of the present study lies in the variety of topics in combination with the limited number of papers that could be included; this restricted the comparisons that could be made. In conclusion, novel biomarkers in screening for and diagnosing pre-eclampsia show promise, but their accuracy is a major driver of cost effectiveness, as is prevalence. Universal screening for pre-eclampsia, using a biomarker, will be feasible only when accuracy is significantly increased. 


\section{Key Points for Decision Makers}

In the field of pre-eclampsia, very few costeffectiveness studies have been performed.

Because of substantial variations in the aims and results of these studies, no unequivocal conclusions can be drawn as to what constitutes cost-effective care in pre-eclampsia.

Limited data exist to support the cost effectiveness of biomarkers for pre-eclampsia.

\section{Introduction}

Pre-eclampsia is a pregnancy complication that is typically characterized by new-onset hypertension and proteinuria after 20 weeks of gestation and affects both mother and fetus. The pathogenesis of pre-eclampsia is not well understood, and the only treatment proven to be effective is delivery. Accurate incidence figures are difficult to obtain, and the incidence varies between countries, but it is believed that worldwide, 3-5\% of pregnant women are affected [1]. In economically poor regions, where there is often only very limited antenatal and intrapartum care, preeclampsia is a severely life-threatening condition, reflected by the fact that it is one of the leading causes of maternal mortality [2]. Pre-eclampsia is also a leading cause $(23.6 \%)$ of perinatal death in economically poor countries [3]. In economically rich countries, pre-eclampsia is less lethal in an absolute sense, although the condition is responsible for around $13 \%$ of maternal deaths [2]; enhanced surveillance and diagnostic possibilities enable more timely and better detection, which, in turn, leads to higher rates of iatrogenic preterm birth, and pre-eclampsia is responsible for occupancy of up to $20 \%$ of neonatal intensive care unit cots [4]. Although there is no proven effective method to prevent pre-eclampsia, screening and early identification of women at risk of pre-eclampsia could enable appropriate application of antenatal care, management and treatment. Screening includes testing, usually in the first half of pregnancy, to identify women at increased risk of pre-eclampsia [5]. At present, preeclampsia screening consists of assessing clinical risk factors such as age, body mass index (BMI) and family history, in combination with an ultrasound scan at 20 weeks. However, an international cohort project determined that the predictive power of clinical risk factors was modest [6]. Recently, several maternal serum markers have been assessed as novel candidates for predicting preeclampsia. Placental growth factor (PIGF), pregnancy- associated plasma protein A (PAPP-A) [7-9], first trimester placental protein-13 $[10,11]$ and soluble fms-like tyrosine kinase-1 (sFlt-1) [12] are some of the potential biomarkers for detecting the development of pre-eclampsia. However, a systematic review by Kleinrouweler et al [13]. on the accuracy of PIGF and sFLT-1 (among other tests) concluded that test accuracy was too poor to adequately predict pre-eclampsia in clinical practice, although the tests might be useful when incorporated into multivariable prediction models. Kenny et al [14]. combined clinical factors and measurements of previously reported biomarkers for preeclampsia risk in women recruited for the Screening for Pregnancy Endpoints (SCOPE) study of low-risk nulliparous women; combining multiple biomarkers and clinical and ultrasound data again provided only a modest prediction of pre-eclampsia. Future developments seem likely to rely on untargeted '-omic' discovery strategies that appear to show promise $[15,16]$. Once patients have been identified as being at high risk of developing preeclampsia, treatment options for prevention are relatively limited. The American College of Obstetricians and Gynecologists (ACOG) and the World Health Organization (WHO) recommend daily low-dose aspirin $(60-80 \mathrm{mg}$ ) $[17,18]$. In addition, the WHO recommends calcium (1.5-2.0 g per day), especially in areas where dietary calcium intake is low [18]. However, the quality of the evidence underlying these recommendations is only moderate. Explicitly not recommended are vitamin $\mathrm{C}$ and $\mathrm{E}$ supplementation, restriction of dietary salt intake, and bedrest $[17,18]$. Treatment for patients who have developed preeclampsia or eclampsia mainly consists of intensified management, magnesium sulphate for prevention of eclampsia and convulsions, and, at a certain point, induction of labour [17, 18]. Naturally, induction of labour necessitates hospital admission, and in some cases intensified management may also require inpatient monitoring.

Compared with the extensive clinical research, the literature on economic evaluations in pre-eclampsia is rather limited. As the scarcity of resources contrasts with the seemingly ever-increasing possibilities in diagnostic, treatment and preventive techniques, it is essential to analyse the association between the resources used and the related effects of any given medical intervention [19]. Health economic assessments can provide relevant insights into safe, effective and efficient health care for health care decision makers at all levels [20, 21]. While economic evaluations address the efficiency of two or more alternatives in terms of both costs and health consequences, often expressed as the incremental cost per quality-adjusted life-year (QALY) gained, the purpose of budget impact analysis (BIA) is to investigate the financial impact of introducing new health care intervention(s) in terms of estimating affordability instead of assessing value for money [22]. 
This study is intended to provide, by means of a systematic review, a comprehensive insight into the existing health economic evidence (either economic evaluations or BIAs) of screening, diagnosis and treatment options for pre-eclampsia.

\section{Methods}

\subsection{Search Strategy}

Three electronic databases (PubMed, EMBASE and the Cochrane Library) were examined in March 2015 to investigate eligible reports/studies of screening, diagnosis, treatment and prevention of pre-eclampsia in the last 20 years (1994-2014). The search terms for all databases were (pre-eclampsia OR 'pre eclampsia') AND (screening OR diagnosis*) AND (prevent* OR intervention) AND (treatment OR manage*) AND ('cost of illness' OR 'cost analysis' OR 'cost effectiveness' OR 'cost benefit' OR 'cost utility' OR 'economic evaluation' OR 'economic analysis' OR 'budget impact'). We included only studies that were performed in humans. Papers not written in English were excluded. For the Cochrane Library, inclusion was limited to economic evaluations.

\subsection{Study Selection and Data Extraction}

The initial screening was based on the title and abstract, followed by a full-text review of the selected articles. In this review, only complete economic assessments in preeclampsia, classified as economic evaluations and/or BIAs, were included. Additionally, economic evaluations were categorized as cost analysis (CA), cost-effectiveness analysis (CEA), cost-utility analysis (CUA) or cost-benefit analysis (CBA). Furthermore, studies were included if they contained a clear description of the methods used. Irretrievable references, poster presentations and meeting abstracts were excluded. For comparability of results across studies, all costs reported in the included papers were set to 2014 US dollar (USD) values by using inflation rates from the World Bank annual consumer price index, as well as purchasing power parities (PPPs) [23].

\subsection{Quality of Reporting}

The checklist for appraising the quality of reporting of the economic evaluation studies was based on the recently published Consolidated Health Economic Evaluation Reporting Standards (CHEERS) statement from the International Society For Pharmacoeconomics and Outcomes Research (ISPOR) Consolidated Health Economic Evaluation Reporting Standards Task Force [24]. The CHEERS statement is the reporting guidance in economic evaluation, which incorporates several previously available guidelines, including the most widely used BMJ checklist $[20,21]$. While a checklist for assessing economic evaluation studies was available and had previously been used extensively, the methods for appraising BIAs were limited. Therefore, we used the guidelines on the reporting format for BIAs, which was based on the Principles of Good Practice for Budget Impact Analysis published by the ISPOR Task Force on Good Research Practices-Budget Impact Analysis [22]. The full CHEERS checklist is shown in Table I of the Electronic Supplementary Material.

\section{Results}

\subsection{Systematic Search}

The search discovered 138 references $(41,85$ and 12 articles from PubMed, EMBASE and the Cochrane Library, respectively), of which 119 remained after cleaning for duplicates. Screening of the title and abstract of these references excluded 111 references, of which 69 were clearly outside the topic of our research interest, such as research about other maternal issues in pregnancy (for example, gestational diabetes mellitus), 39 references were not economic evaluation studies, one study was outside our date limits (i.e. published before 1994) and the other two were not written in English. On the basis of this screening, eight references met the inclusion criteria. Two of these were excluded because they were not full papers but conference proceedings. Of the remaining six references, the full text was screened, resulting in final inclusion of six references [25-30], as shown in Fig. 1, of which five were economic evaluation studies and the remaining one was a BIA. Three studies addressed screening and/or diagnosis and included subsequent events, whereas the other three focused on treatment strategies after diagnosis of preeclampsia. In the remainder of this section, each study is discussed separately, guided by the respective checklists when applicable. The design and results are addressed, as well as strengths and limitations. An overview of the main study characteristics is provided in Table 1, information on cost categories included and price level is reflected in Table 2 and a summary of the main findings is presented in Table 3.

\subsection{Summary of Included Studies}

\subsubsection{Studies on Screening and Diagnosis}

Three studies on the topic of screening and diagnosis were included in the review. Shmueli et al. [27] performed a 
Fig. 1 Selection of references in systematic review

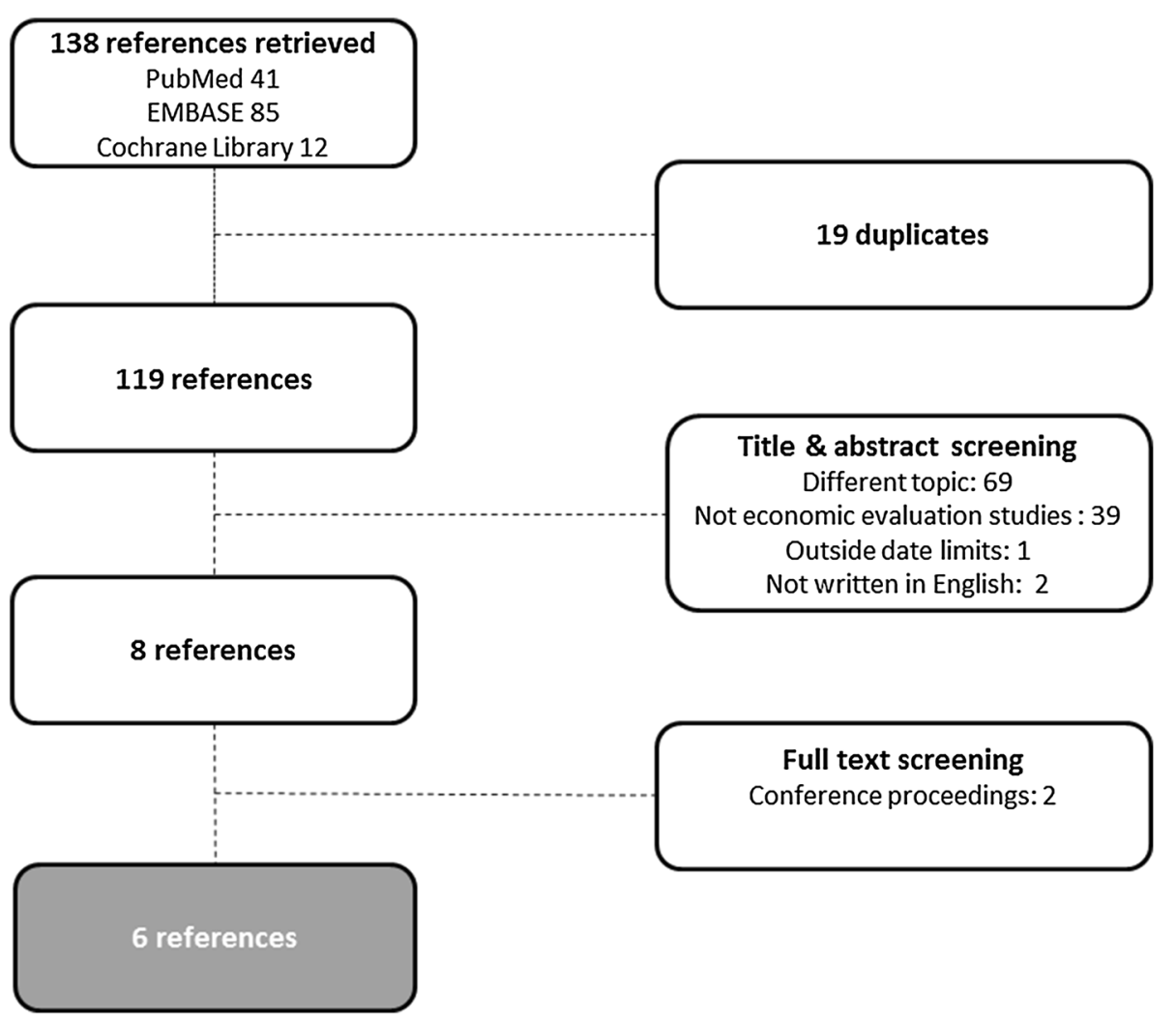

CEA, by means of a model, of routine first-trimester screening for pre-eclampsia, using placental markersplacental protein-13 and PIGF-and uterine artery Doppler, as compared with standard care in an Israeli setting. The detection rates of screening were assumed to be $70 \%$ for late cases of pre-eclampsia and $90 \%$ for early cases, on the basis of a previous study [31], with a false negative rate of $10 \%$. Screen-positive cases were managed in the same manner as women with risk factors, i.e. the highest frequency of doctor visits and administration of preventive measures (any of aspirin, calcium, vitamin D, folic acid and prenatal multivitamins, or a combination of these). The time horizon was set at 30 years because follow-up of the child was considered for the analysis, including the risks of stillbirth, life expectancy and quality of life up to the age of 30 years [27]. Pre-eclampsia was assumed to be associated with more preterm births, a higher rate of caesarean section and a higher rate of admission to a neonatal intensive care unit, as well as a higher rate of diabetes mellitus type 2 at the age of 32 years [27, 32]. For input parameters concerning prevalence, time and mode of delivery, and bed rest prior to delivery, retrospective data from a Haifa hospital were used. As a consequence, the results were quite specific to the Israeli setting, but this was made clear in the paper. The prevalence for the base case was set at $1.7 \%$, which can be considered rather low given the 2-8 \% prevalence reported elsewhere [33, 34]. The outcomes were the incremental cost per pre-eclampsia case prevented and the incremental cost per QALY of the offspring gained by screening. Univariate sensitivity analysis was performed on five major parameters: the test cost, the false positive rate, the pre-eclampsia prevalence, the test's detection rate, and the effectiveness of the preventive measures (i.e. calcium supplementation and low-dose aspirin). The conclusion of the authors was that screening for pre-eclampsia is cost effective from the payer perspective under various scenarios. The results were sensitive to changes in each of the parameters that varied in the sensitivity analysis. In addition, the time horizon was an important driver of cost effectiveness, in the sense that extending the time horizon resulted in a more favourable incremental cost-effectiveness ratio (ICER) for screening as compared with no screening.

Possible limitations of this study were that there was no probabilistic sensitivity analysis, even though this is recommended by guidelines on economic modelling [35] and is regarded as standard practice nowadays. Also, there was no report on model validation. Another limitation may have been the choice of model structure. Given the decision problem at hand, which concerned calculating longterm costs and effects, the analysis might have been better served by using a Markov model, as the choice of a decision tree seems to have forced the authors to oversimplify the sequence of events in the long term, resulting in 
Table 1 Overview of main study characteristics of the economic evaluations included

\begin{tabular}{|c|c|c|c|c|c|c|c|c|}
\hline \multirow[t]{3}{*}{ Study } & \multicolumn{3}{|c|}{ Study design } & \multicolumn{5}{|l|}{ Analysis } \\
\hline & \multirow{2}{*}{$\begin{array}{l}\text { Method } \\
\text { and } \\
\text { perspective }\end{array}$} & \multirow[t]{2}{*}{ Perspective } & \multirow[t]{2}{*}{ Alternatives compared } & \multirow[t]{2}{*}{$\begin{array}{l}\text { Time } \\
\text { horizon }\end{array}$} & \multicolumn{2}{|c|}{$\begin{array}{l}\text { Discount rates } \\
(\%)\end{array}$} & \multirow[t]{2}{*}{$\begin{array}{l}\text { Sensitivity } \\
\text { analysis }\end{array}$} & \multirow[t]{2}{*}{$\begin{array}{l}\text { Parameters in the sensitivity } \\
\text { analysis }\end{array}$} \\
\hline & & & & & Costs & Effects & & \\
\hline \multicolumn{9}{|c|}{ Screening and diagnosis } \\
\hline $\begin{array}{l}\text { Shmueli } \\
{[27]}\end{array}$ & $\begin{array}{l}\text { Decision } \\
\text { tree }\end{array}$ & Payer & $\begin{array}{l}\text { No screening versus } \\
\text { screening for placental } \\
\text { protein-13, placental } \\
\text { growth factor and } \\
\text { uterine artery Doppler } \\
\text { pulsatility index }\end{array}$ & 30 years & 3 & 3 & $\begin{array}{l}\text { Best- and } \\
\text { worst-case } \\
\text { scenarios }\end{array}$ & $\begin{array}{l}\text { False positive rate, test cost, } \\
\text { pre-eclampsia prevalence, } \\
\text { test's detection rate, } \\
\text { effectiveness of preventive } \\
\text { measures (measured as the } \\
\text { proportion of women } \\
\text { whose pre-eclampsia was } \\
\text { not prevented by the } \\
\text { preventive procedures) }\end{array}$ \\
\hline $\begin{array}{l}\text { Meads } \\
{[26]}\end{array}$ & $\begin{array}{l}\text { Decision } \\
\text { tree }\end{array}$ & $\begin{array}{l}\text { Health care } \\
\text { decision } \\
\text { maker }\end{array}$ & $\begin{array}{l}\text { No intervention versus } \\
\text { intervention (in a wide } \\
\text { range of different } \\
\text { testing and treatment } \\
\text { options) }\end{array}$ & NR & NR & NR & $\begin{array}{l}\text { Probabilistic } \\
\text { sensitivity } \\
\text { analysis }\end{array}$ & $\begin{array}{l}\text { Sensitivity and specificity of } \\
\text { the test, prevalence rates, } \\
\text { cost of pre-eclampsia }\end{array}$ \\
\hline $\begin{array}{l}\text { Hadker } \\
{[25]}\end{array}$ & $\begin{array}{l}\text { Decision } \\
\text { tree }\end{array}$ & $\begin{array}{l}\text { UK health } \\
\text { care } \\
\text { payer }\end{array}$ & $\begin{array}{l}\text { Standard pre-eclampsia } \\
\text { diagnostic practice } \\
\text { versus standard } \\
\text { practice + novel pre- } \\
\text { eclampsia test using } \\
\text { biomarkers }\end{array}$ & NR & NA & NA & Univariate & $\begin{array}{l}\text { Pre-eclampsia incidence rate, } \\
\text { sensitivity of current tests, } \\
\text { specificity of current tests, } \\
\text { proportion of patients } \\
\text { stratified as being at high } \\
\text { risk of pre-eclampsia, cost } \\
\text { of the novel pre-eclampsia } \\
\text { test }\end{array}$ \\
\hline \multicolumn{9}{|l|}{ Treatment } \\
\hline $\begin{array}{l}\text { Vijgen } \\
{[29]}\end{array}$ & $\begin{array}{l}\text { Trial- } \\
\text { based } \\
\text { CEA }\end{array}$ & Societal & $\begin{array}{l}\text { Labour induction } \\
\text { compared with } \\
\text { expectant monitoring } \\
\text { in women with pre- } \\
\text { eclampsia at term }\end{array}$ & 1 year & NA & NA & Univariate & $\begin{array}{l}\text { Labour and operating theatre } \\
\text { costs, delivery costs, } \\
\text { antepartum admission } \\
\text { costs, neonatal ward } \\
\text { admission costs, no } \\
\text { separation in admission } \\
\text { phase, values of } \\
\text { admissions using lower/ } \\
\text { higher unit costs }\end{array}$ \\
\hline $\begin{array}{l}\text { Simon } \\
{[28]}\end{array}$ & $\begin{array}{l}\text { Trial- } \\
\text { based } \\
\text { CEA }\end{array}$ & $\begin{array}{l}\text { Treatment } \\
\text { provider } \\
\text { (hospital) }\end{array}$ & $\begin{array}{l}\text { Magnesium sulphate for } \\
\text { pre-eclampsia in } 3 \\
\text { categories of countries } \\
\text { grouped by GNI }\end{array}$ & $<1$ year & NA & NA & Univariate & $\begin{array}{l}\text { Severity of pre-eclampsia, } \\
\text { relative risk of pre- } \\
\text { eclampsia, cost of } \\
\text { magnesium sulphate }\end{array}$ \\
\hline $\begin{array}{l}\text { Blackwell } \\
{[30]}\end{array}$ & $\begin{array}{l}\text { Decision } \\
\text { tree }\end{array}$ & NR & $\begin{array}{l}\text { Seizure prophylaxis with } \\
\text { magnesium sulphate } \\
\text { versus control group } \\
\text { with no prophylaxis }\end{array}$ & 30 years & 3 & 0 & Univariate & $\begin{array}{l}\text { Incidence of pre-eclampsia, } \\
\text { incidence of severe pre- } \\
\text { eclampsia, seizure rate } \\
\text { with severe pre-eclampsia, } \\
\text { seizure rate with mild pre- } \\
\text { eclampsia, non-preventable } \\
\text { seizure rate, mortality from } \\
\text { eclampsia, efficacy of } \\
\text { magnesium sulphate }\end{array}$ \\
\hline
\end{tabular}

$C E A$ cost-effectiveness analysis, $G N I$ gross national income, $N A$ not applicable, $N R$ not reported

basically only two possible outcomes in the model for offspring surviving the first year: either diabetes at the age of 32 years or no diabetes at the age of 32 years.

The study by Meads et al. [26] was a health technology assessment (HTA) report and incorporated both a systematic review and a meta-analysis, as well as a costeffectiveness model. The aim of the study was to compare the effectiveness and cost effectiveness of different combinations of screening and treatment strategies for preeclampsia in the UK setting. The combinations tested in the 
Table 2 Categories of included costs in economic evaluation of screening, diagnosis, treatment and prevention for pre-eclampsia

\begin{tabular}{|c|c|c|}
\hline Study & Categories of included costs & $\begin{array}{l}\text { Currency, price } \\
\text { year }\end{array}$ \\
\hline \multicolumn{3}{|c|}{ Screening and diagnosis } \\
\hline $\begin{array}{l}\text { Shmueli } \\
\text { [27] }\end{array}$ & $\begin{array}{l}\text { Screening test cost, supplement and medication cost, cost of visit frequency, cost of prenatal care, pre- } \\
\text { delivery hospitalization, maternal and neonatal costs, offspring's lifetime costs considering 30-year } \\
\text { follow-up }\end{array}$ & $\begin{array}{l}\text { Price year not } \\
\text { mentioned }\end{array}$ \\
\hline $\begin{array}{l}\text { Meads } \\
{[26]}\end{array}$ & $\begin{array}{l}\text { Test costs (body mass index measurements, maternal serum } \alpha \text {-fetoprotein, cellular fibronectin, total } \\
\text { fibronectin, fetal DNA, maternal serum human chorionic gonadotropin, serum unconjugated oestriol, } \\
\text { serum uric acid, urinary calcium excretion, urinary calcium creatinine ratio, total proteinuria, albuminuria, } \\
\text { microalbuminuria, albumin/creatinine ratio, Doppler examinations), treatment costs (antioxidants, } \\
\text { calcium, garlic, magnesium, fish oils, medications [antihypertensive, antiplatelet, diuretic, nitric oxide, } \\
\text { progesterone]), intervention costs, pre-eclampsia costs (including all hospital costs for mother and baby, } \\
\text { without costs of normal delivery) }\end{array}$ & GBP, 2005-2006 \\
\hline $\begin{array}{l}\text { Hadker } \\
{[25]}\end{array}$ & $\begin{array}{l}\text { Pre-eclampsia assessment costs, drug costs, pre-eclampsia management costs (physician office visits, } \\
\text { physical exams, regular blood pressure checks, blood and urine tests and cardiotocography, as well as } \\
\text { hospital stays for day assessments, intensive care, inpatient monitoring and delivery or termination of } \\
\text { pregnancy), cost of the novel test, and cost of all testing }\end{array}$ & $\begin{array}{l}\text { Price year not } \\
\text { mentioned }\end{array}$ \\
\hline \multicolumn{3}{|l|}{ Treatment } \\
\hline $\begin{array}{l}\text { Vijgen } \\
{[29]}\end{array}$ & $\begin{array}{l}\text { Direct medical costs: hospital stay (mother and child), specialist care, outpatient visit, psychologist, } \\
\text { midwife, general practitioner, paramedical, home care, day care, induction methods, medications } \\
\text { (antihypertensive medication and antibiotics, analgesics during labour), neonatal monitoring, operation } \\
\text { room, labour room. Direct non-medical costs: modes of travelling to hospital and use of informal care } \\
\text { given by partner or family. Indirect medical costs: sick leave from work }\end{array}$ & EUR, 2007 \\
\hline $\begin{array}{l}\text { Simon } \\
{[28]}\end{array}$ & $\begin{array}{l}\text { Total cost was calculated as the sum of treatment and other costs. Treatment cost included magnesium } \\
\text { sulphate and its administration (staffing, equipment, consumables). Other costs covered all other aspects of } \\
\text { hospital care in the trial, such as treating pre-eclampsia, eclampsia, and side effects of magnesium sulphate } \\
\text { treatment; and costs of antenatal and postnatal ward stay, high dependency and/or intensive care, artificial } \\
\text { ventilation, delivery and medication for the mother and the costs of the hospital stay, neonatal intensive } \\
\text { care and artificial ventilation for the baby }\end{array}$ & USD, 2001 \\
\hline $\begin{array}{l}\text { Blackwell } \\
{[30]}\end{array}$ & Drug cost, pharmacy personnel time charges & $\begin{array}{l}\text { Price year not } \\
\text { mentioned }\end{array}$ \\
\hline
\end{tabular}

model were numerous, with these five general strategies used to represent the approaches: (i) no test and no treatment; (ii) no test and treat all; (iii) test all and no treatment; (iv) test all and treat only those with positive test result; and (v) test all and treat all. Only those treatments that were found (in the meta-analysis) to be unlikely to have a negative effect (i.e. to result in more cases of pre-eclampsia, defined as a confidence interval of the odds ratio entirely $<1)$ were considered in the base-case economic analysis. These treatments were rest at home, antiplatelets, antioxidants and calcium, and each was combined in the model with a wide range of tests, e.g. maternal serum human chorionic gonadotropin (HCG), total fibronectin (FN), total proteinuria and the Doppler uterine artery pulsatility index. Estimates of test accuracy used in the model were also obtained from the project's meta-analysis. The model results demonstrated that from the perspective of the UK National Health Service, the most cost-effective strategy was to recommend rest for all women without prior testing, followed by treatment of all women with calcium supplementation, also without initial testing. The preference for a no-test strategy was caused by the relatively poor accuracy of the tests as reported in the accompanying systematic review. In addition, the authors stated that the pattern of cost effectiveness did not differ between the high-risk mothers and low-risk mothers considered in the base case, and that there is little evidence to indicate that any form of Doppler test is accurate enough to be cost effective for early identification of pre-eclampsia. Meads et al. [26] did perform a probabilistic sensitivity analysis, but there was no report on model validation. There was no report on discount rates either, but, given that the analysis only covered the duration of the pregnancy, discounting was not relevant. For the same reason, the choice of a decision tree seems suitable. A rather serious drawback of the analysis, which was also mentioned by the authors in their discussion, is that all tests were considered separately, using their stand-alone accuracy. Even though combinations of tests, as well as combinations of tests and clinical judgment, would probably be more accurate and also more reflective of clinical practice than using one test by itself, there was no evidence regarding the sensitivity and specificity of these combinations; therefore, they could not be incorporated into the model. Given this limitation, the importance of the cost-effectiveness results was confined to the context of single testing only. 
Table 3 Main findings (values are expressed in 2014 USD)

\begin{tabular}{|c|c|}
\hline Study & Main findings \\
\hline \multicolumn{2}{|c|}{ Screening and diagnosis approaches } \\
\hline Shmueli [27] & $\begin{array}{l}\text { From a payer perspective, screening for pre-eclampsia is cost effective under various scenarios } \\
\text { The incremental cost per pre-eclampsia case averted is } \$ 68,973 \text { (prevalence } 1.7 \% \text { ) } \\
\text { Early screening: } \$ 19,491 \text { per QALY gained (prevalence } 1.7 \% \text { ) } \\
\text { With a test cost of } \$ 115 \text {, the total cost until discharge with/without screening is equal; at a prevalence of } 3 \% \text {, screening is } \\
\text { cheaper }\end{array}$ \\
\hline Meads [26] & $\begin{array}{l}\text { From a decision maker viewpoint, giving calcium supplementation to all pregnant women ('no test/calcium all)' without any } \\
\text { initial testing is the most effective 'test/treatment' combination }\end{array}$ \\
\hline Hadker [25] & $\begin{array}{l}\text { The model estimated that the costs of a typical pregnancy are } \$ 2919 \text { per patient when the new test is used, as compared with } \\
\$ 4468 \text { without the test (standard practice); this represents savings of } \$ 1549 \text { per pregnant woman; the savings are attributed to } \\
\text { the new test's improved accuracy }\end{array}$ \\
\hline \multicolumn{2}{|c|}{ Treatment approaches } \\
\hline Vijgen [29] & $\begin{array}{l}\text { From a societal point of view, induction of delivery is cost effective compared with expectant monitoring in term pre-eclampsia; } \\
\text { induction does not result in a higher rate of caesarean section, while fewer patients progress to severe disease }\end{array}$ \\
\hline Simon $[28]$ & $\begin{array}{l}\text { From a hospital perspective, use of magnesium sulphate prevents more cases of eclampsia in low-GNI countries than in high- } \\
\text { GNI countries } \\
\text { High-GNI countries: } \$ 28,335 \text { per case of eclampsia prevented } \\
\text { Middle-GNI countries: } \$ 3,305 \text { per case of eclampsia prevented } \\
\text { Low-GNI countries: } \$ 609 \text { per case of eclampsia prevented } \\
\text { Also, treating only severe cases of pre-eclampsia substantially lowers the ICER, i.e. has a more favourable cost-to-effect ratio }\end{array}$ \\
\hline $\begin{array}{l}\text { Blackwell } \\
{[30]}\end{array}$ & $\begin{array}{l}\text { Universal prophylaxis using magnesium sulphate for all women with pre-eclampsia is cost effective compared with the strategy } \\
\text { of treating only those with severe disease; ICER for universal compared with selected strategy: } \$ 13,356 \text { per seizure prevented } \\
\text { and } \$ 626,782 \text { per death averted, which is considered cost effective assuming } 1 \text { death averted saves on average } 30 \text { life-years } \\
\text { and given a threshold of } \$ 50,000 \text { per life-year gained }\end{array}$ \\
\hline
\end{tabular}

GNI gross national income, ICER incremental cost-effectiveness ratio, $Q A L Y$ quality-adjusted life-year

Another study on screening was a BIA by Hadker et al. [25], which analysed the financial consequences, in the UK setting, of implementing a novel biomarker test for preeclampsia. As a BIA is applied to a specific health care setting, it is recommended that the data sources represent the circumstances in the setting [22]. The clinical data of the included BIA study were derived from the relevant literature, as well as local UK databases and interviews. The test under investigation consisted of two biomarkers, PIGF and sFlt-1, and was assumed to have a sensitivity of $82 \%$ and a specificity of $95 \%$ after 20 weeks of gestation, as calculated from a multicentre case-control study [36]. The novel test was compared with current practice, which included blood tests such as serum uric acid, urine tests (to screen for proteinuria), blood pressure measurements and uterine artery Doppler ultrasounds. Accuracy estimates for the diagnostic tests performed in current practice were taken from Meads et al. [26]. The time horizon of the model was from the booking period (12 weeks) to term (40 weeks). Because of the improved sensitivity and specificity of the novel test, false positives were reduced, while true positives were increased. Even though the novel test increased test costs, treatment costs were reduced because there were fewer false positive patients who received unnecessary management and also fewer false negative patients who were not treated properly and would therefore incur costs later on. From the hypothetical cohort of 1000 pregnant women, it was estimated that in summary, the novel test was cost saving compared with standard practice [25].

\subsubsection{Studies on Treatment}

The other three studies included in the review were on the topic of treatment for pre-eclampsia. The study by Vijgen et al. [29] was conducted alongside the Dutch Hypertension and Pre-eclampsia Intervention Trial at Term (HYPITAT) trial [37] and evaluated the economic consequences of delivery induction compared with expectant monitoring in women with mild pre-eclampsia at term. In the trial, women with gestational hypertension or pre-eclampsia between 36 and 41 weeks of gestation were randomly allocated to either expectant monitoring $(n=379)$ or induction of delivery $(n=377)$. In the expectant-monitoring group, patients were monitored until spontaneous delivery, whereas in the induction group, delivery was induced within $24 \mathrm{~h}$ after randomization. The CEA was performed from a societal perspective, i.e. including productivity costs. The results showed that induction of 
delivery was less costly than expectant monitoring, mostly because of the differences in resource use in the antepartum period. As the HYPITAT trial had already demonstrated that induction of labour results in less progression to severe disease but does not increase the rate of caesarean sections, both costs and effectiveness were more favourable in the induction group. Induction of labour was also least expensive in all of the sensitivity analyses that were performed. The HYPITAT trial [37] was a Dutch study, and since the Dutch model for pregnancy care is rather unique [38], the conclusions of this trial may not hold in other countries and health care systems, i.e. the population with gestational hypertension or pre-eclampsia referred for secondary care in the Netherlands may not be representative of the global or European situation.

The other two included studies assessed the use of magnesium sulphate. Simon et al. [28] evaluated cost effectiveness alongside the large international Magnesium Sulphate for Prevention of Eclampsia (Magpie) trial, which compared magnesium sulphate with placebo in 9996 women with preeclampsia in 333 countries [39]. Patients included in the study were randomly allocated to receive either a placebo or magnesium sulphate (intramuscularly or intravenously, at the discretion of the physician). The CEA was performed from a hospital perspective and distinguished between high-, middle- and low-income countries. The costs included in the analysis were the costs of treatment (magnesium sulphate and its administration) and 'other' costs for treating preeclampsia, eclampsia or the side effects of magnesium sulphate treatment. The study showed that in low-gross national income (GNI) countries, magnesium sulphate averts more eclampsia than in high-GNI countries, because in low-GNI countries, the baseline prevalence of pre-eclampsia is higher, which increases the absolute risk reduction. Therefore, magnesium sulphate for pre-eclampsia was found to be most cost effective in low-income countries. In addition, cost effectiveness would be considerably improved in all income categories if only severe pre-eclampsia was treated with magnesium sulphate, or if the purchase price in low-income countries could be reduced. The Magpie trial [39] was performed in many countries, with almost complete follow-up ( $>99 \%$ ), and reported the CEA separately for low-, middleand high-income countries, facilitating translation to other settings.

Blackwell et al. [30] also evaluated the cost effectiveness of magnesium sulphate in pregnancies complicated by pre-eclampsia, by means of a decision model comparing three strategies, i.e. no anticonvulsant therapy, selective prophylaxis for patients with severe pre-eclampsia and universal prophylaxis for all patients with pre-eclampsia. The clinical consequences were described as development of eclampsia or maternal death associated with eclampsia, and cost effectiveness was expressed as the cost per seizure averted and the cost per maternal death averted. The authors chose to use a decision tree, which seems perfectly appropriate. Inputs for the model were derived from the literature available at the time, which did not yet include the results of the Magpie trial. The analysis was performed for the US setting. Costs included in the model seemed to be limited to the cost of magnesium sulphate injections and associated personnel time for administration. So the possible cost consequences due to treating seizures or the side effects of magnesium sulphate, for example, were not considered. Given this information, the perspective of the economic evaluation was not clear, because the authors did not explicitly state what the perspective was, and only some of the hospital costs were taken into account. The authors argued that universal treatment of all women with pre-eclampsia is a more cost-effective option than the selective strategy. Even though the incremental cost effectiveness resulting from the analysis was substantial, it would still be below the threshold of $\$ 50,000$ per life-year gained if one assumes that one death averted equals 30 lifeyears gained. In this calculation, costs were discounted at $3 \%$, but the effects were not, which may be considered questionable given the guidelines on this [40]. Probabilistic sensitivity analysis was not performed. The input parameters were varied in a univariate sensitivity analysis-but solely to judge their impact on seizures and deaths averted, not on cost effectiveness. For cost effectiveness, only the impact of a change in the price of magnesium sulphate was investigated, implicitly assuming that other parameters do not matter in this respect, even though the efficacy of magnesium sulphate had a significant impact on seizures and deaths averted in both the universal treatment strategy and the selective treatment strategy. Furthermore, the impact of varying the price of magnesium sulphate on incremental cost effectiveness was not clear from the paper.

\subsection{Assessment of Quality of Reporting}

An overview of the appraisal of the reporting format for all included studies is presented in Table 4. The issues on which the studies complied least with the recommendations of both CHEERS and the BIA reporting format mostly concerned methods. The discount rate for both costs and outcomes (item 9), measurement of effectiveness (items $11 \mathrm{a}$ and $11 \mathrm{~b}$ ), measurement and valuation of preferencebased outcomes (item 12), estimation of resources and costs (items 13a and 13b), rationale for choice of decisionanalytical model type (item 15) and description of analytical methods supporting the evaluation (such as extrapolation methods, approaches to validate the model, etc.) (item 17) appeared to be the items that were frequently only partially reported or were not reported at all. In 


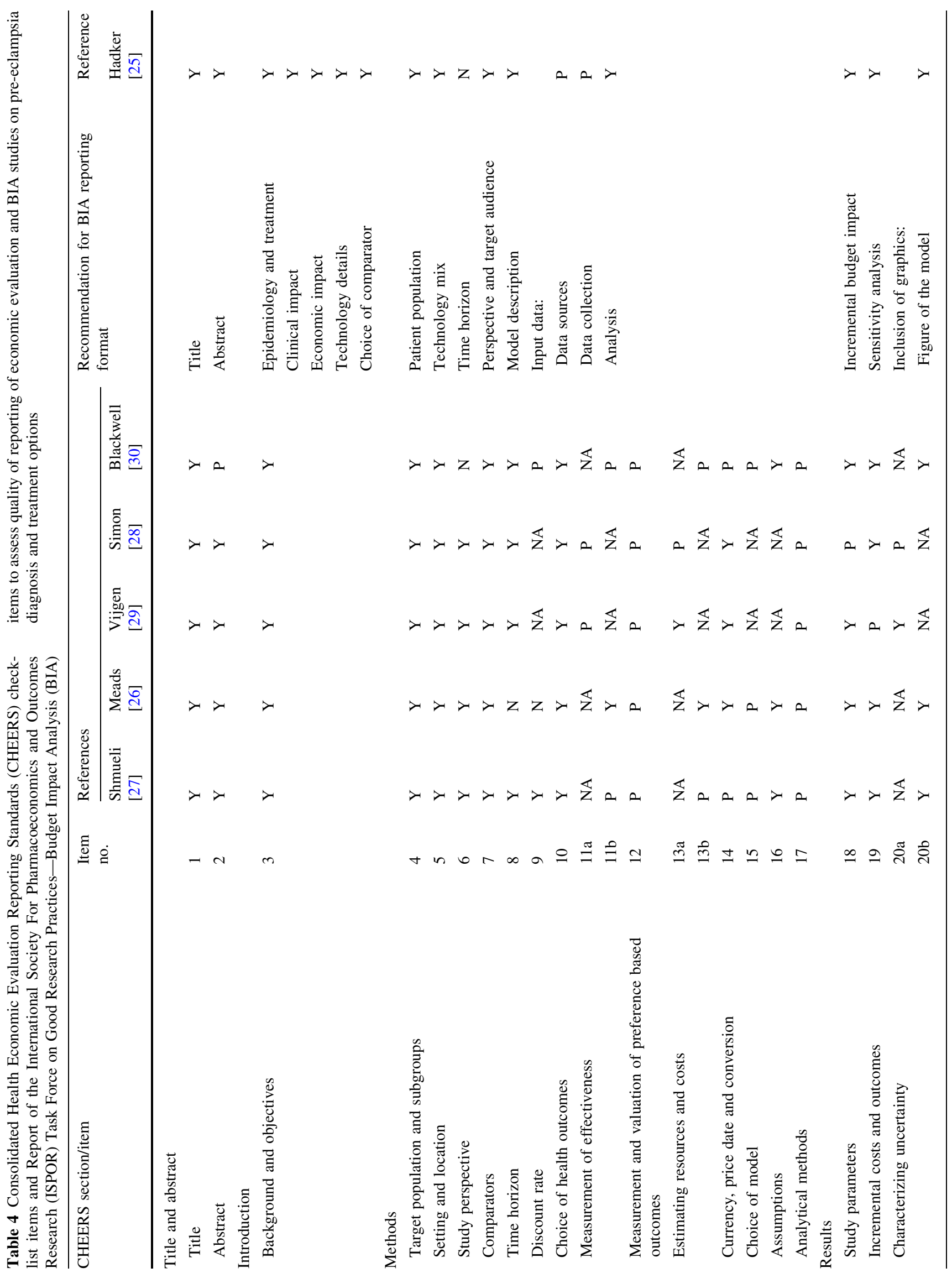




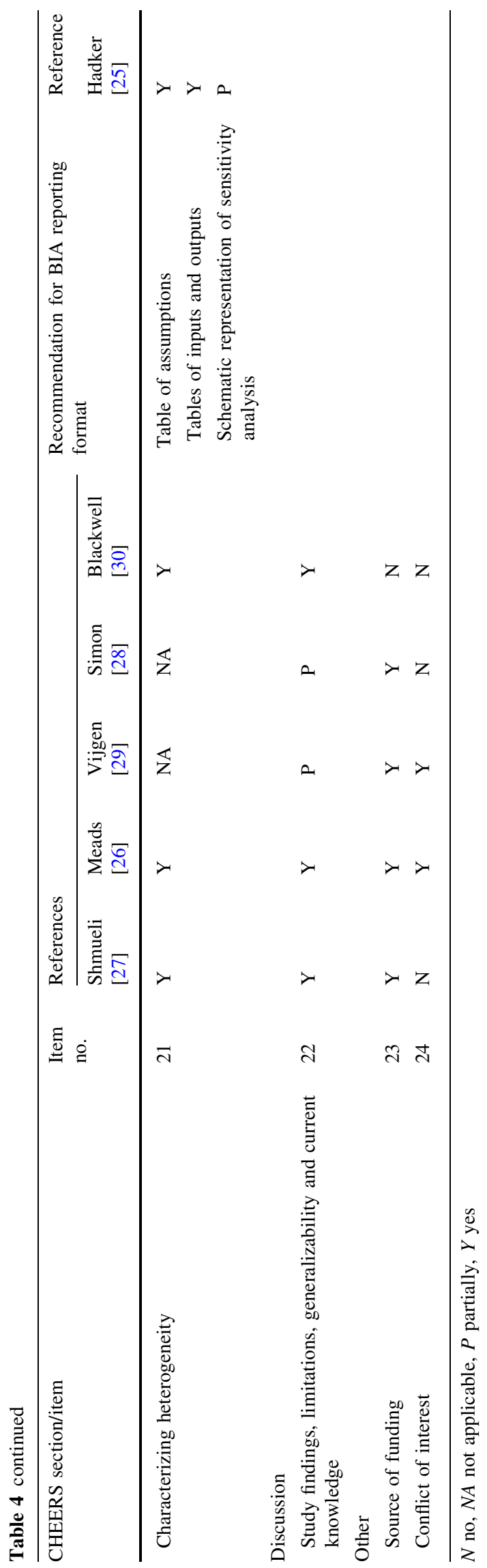

addition, the justification of the choice of comparator, study perspective and time horizon were not reported in some studies. In the BIA study, input data items were only partially reported. In addition, a discussion of strengths, weaknesses and possible sources of bias that might have been inherent in the data used in the analysis, as well as a description of methods and processes for primary data collection and data abstraction, were not present in the included BIA study.

Incremental costs and outcomes and study findings, both in results and discussion sections, were generally reported in all studies, as summarized in Table 3. However, some studies did not provide a discussion of the limitations and generalizability of their findings. Almost all studies stated their source of funding. Nevertheless, only half of the studies reported on conflicts of interest.

Most of the studies were published in obstetrics and gynaecology journals [27-30], and one study was published in a health economic journal [25], whereas the study by Meads et al. [26] was-as was inherent in the nature of the research project-published as an HTA report.

\section{Discussion}

A systematic review was conducted to provide an overview of published health economics studies in screening, diagnosis, treatment options and prevention of pre-eclampsia. In this review, we found five relevant and retrievable economic evaluation studies and one BIA study. This review provides a comprehensive insight into the economic aspects of pre-eclampsia, from screening to treatment choices. We used the most recent guidelines on economic evaluation and BIA, which provide comprehensive recommendations to assess such studies. To the best of our knowledge, this is the first review to assess the health economic implications of pre-eclampsia care. Given the recent development of new interventions in the field of preeclampsia, especially in screening and diagnosis, the results of our study are of importance to decision makers and can support the evaluation of health care interventions regarding pre-eclampsia care.

The conclusion provided by the included papers is that screening pregnant women for pre-eclampsia has the potential to be cost effective. Nevertheless, many uncertainties remain. The evidence as to the accuracy of tests, whether alone, in combination with each other, or in combination with clinical judgment, is not strong enough to base solid conclusions on. Two of the screening studies showed a cost-effective screening strategy [25, 27], but in both of these studies the evidence base for the accuracy parameters used in the model was limited. Shmueli et al. [27] derived the detection rate from a study by Akolekar et al. [31], who, in 
turn, derived results partly directly from a trial, but for a number of markers they used data from other studies. In other words, the detection rates used in the cost-effectiveness model have never been observed in a real population using these specific markers. Hadker et al. [25] derived accuracy estimates from a case-control study with 71 pre-eclampsia cases and 268 healthy controls [36], which may be perfectly valid. However, the accuracy of the comparator, or care as usual, is obtained by calculating an average of the sensitivity and specificity of all tests, as reported in the HTA report by Meads et al. [26]. This may introduce bias, as Meads et al. reported on 25 different tests, some of which are admittedly not very good at detecting pre-eclampsia and probably are not part of current care as usual. In addition, as was also explicitly mentioned by Meads et al., their definition of test accuracy applied to single testing, which is not a typical representation of care as usual. Taking these two points together, the pooled accuracy from Meads et al. is likely to be an underestimation of test accuracy in clinical practice, which would result in an overly optimistic view of the budget impact of the novel test.

As for treatment options, the case for induction of labour seems strong compared with expectant monitoring in women with term pre-eclampsia, concerning both effectiveness and cost effectiveness. For the use of magnesium sulphate, the findings are slightly more complicated, as Simon et al. [28] found that the use of magnesium sulphate is particularly cost effective in severe cases of preeclampsia, whereas Blackwell et al. [30] concluded quite the opposite, i.e. that it is more cost effective to treat all women with pre-eclampsia with magnesium sulphate, without considering severity. It is difficult to explain this contradiction, although a possible reason for the difference may lie in the perspectives taken for calculating the costs. Blackwell et al. only took account of the costs of the magnesium sulphate itself plus the costs of its administration, while Simon et al. took a slightly broader perspective and included all hospital costs associated with magnesium sulphate treatment but also with pre-eclampsia per se. This broader perspective may have identified a cost advantage for the group with severe pre-eclampsia in the analysis by Simon et al. That said, the two studies differed in many other respects, and the differences may have been due to the study setting and approaches used to assess resources and costs, as well as the sources of clinical effectiveness data for the analysis.

Regarding the quality of the reporting format for both economic evaluation and BIA studies, we noticed that there were shortcomings in the reporting of details of the methods used in most of the studies. Reporting could also be improved in the introduction section by provision of an explanation or justification for the choice of economic evaluation used in relation to addressing the research questions. Also, a description of values, ranges and references for all parameters and their rationales should be provided in the results section, while each discussion section needs debate on the generalizability of the findings. Although insufficient reporting does not necessarily reflect inadequate study quality, the availability of recommendations such as the CHEERS statement [24] and the BIA Principles of Good Practice for Budget Impact Analysis [22] could be used to improve the reporting quality and thus lead to improved evaluation, transparency and comparability in economic evaluation and BIA studies.

There are several limitations of our review, which lie mainly in the limited number of papers we were able to include, and in the large variety of topics studied and methods used. There were five CEAs and one BIA; four studies were model based and two were trial based; three studies were on some form of screening, two studies were on magnesium sulphate and one was on labour induction in term pre-eclampsia. Besides this, there were vast differences among the included studies concerning the alternatives compared, time horizons and perspectives of the analyses, and the ways in which sensitivity analyses were performed. Therefore, it was not possible to make valid comparisons between studies or draw general conclusions, and so it remains uncertain whether screening for preeclampsia and subsequent prophylactic treatment can be considered cost effective. It seems that, in any case, the currently available screening techniques are not quite accurate enough and lack predictive power in a clinical setting. The two studies on magnesium sulphate were equivocal in their conclusions on the cost effectiveness of also treating non-severe cases of pre-eclampsia. In addition, even though our review was as up to date as possible, it did not include any economic evaluation studies on prophylactic aspirin, which has been added to the National Institute for Health and Care Excellence (NICE) guidelines and is recommended by the WHO [18, 41]. Park et al. [42] showed that prescribing aspirin (150 mg daily) to pregnant women at high risk of developing early-onset preeclampsia could significantly reduce the number of cases. Given the fact that aspirin is inexpensive and conveniently taken, it may very well be a cost-effective option, and this will probably become apparent in the near future.

Individual interpretation of the recommendations could also be a potential limitation for our review. We used 'yes' $(\mathrm{Y})$, 'no' $(\mathrm{N})$, 'partially reported' $(\mathrm{P})$, and 'not applicable' (NA) to assess the quality of reporting, which was based on the interpretation of the reviewers. The 'partially reported' category was necessary because some items in the checklist consisted of multiple recommendations. For instance, in item 17 ('analytical methods') from the CHEERS statement, the recommendation was to describe all analytical methods supporting the evaluation, including methods for 
dealing with skewed, missing or censored data, extrapolation methods, methods for pooling data, approaches to validate or make adjustments to a model, and methods for handling population heterogeneity and uncertainty-and if the study did not provide one of these, then the item was scored as partially reported. This was subject to bias, however, as the difference between fully reported (Y) and partially reported $(\mathrm{P})$ was not always clear.

Importantly, the consequences of pre-eclampsia are not limited to early life; surviving offspring are at much greater risk of cerebral palsy and neurodevelopmental delay, and have increased risks of obesity, cardiovascular disease, hypertension, diabetes and schizophrenia in adulthood [4349]. Global rates of these conditions have increased rapidly [50] and impose massive burdens on public health systems, the economy and society [51, 52]. These burdens will rise further with the trend of decreasing age at disease onset, as evidenced by the increasing prevalence of childhood and adolescent obesity, diabetes, hypertension and cardiometabolic risk factors [53, 54]. The International Monetary Fund (IMF), World Bank, WHO and United Nations (UN) all indicate the need for greater emphasis on maternal and infant health $[55,56]$.

\section{Conclusion}

Novel biomarkers in screening for and diagnosing preeclampsia show promise, but their accuracy is a major driver of cost effectiveness, as is prevalence. Universal screening for pre-eclampsia using a biomarker will be feasible only when accuracy is significantly increased. In addition, the included studies identified the need for more research into-among other things-the long-term consequences of pre-eclampsia, accuracy of combinations of tests/accuracy of tests integrated into a clinical decision rule, and effectiveness of prophylactic treatment strategies. Improvement in the quality of reporting, especially in the methods used, for further economic evaluation studies of diagnosis and treatment options for pre- eclampsia is also needed.

Acknowledgments This research was partly funded by a grant from the European FP7-Health Programme; see also http://www.fp7improved.eu.

Conflict of interest Neily Zakiyah performed the major part of this project as an MSc student at the University of Groningen. Neily Zakiyah is also a part time researcher in reproductive and maternal health at i+Solutions, Netherlands. Philip Baker is a minority shareholder in Metabolomics Diagnostics, a small biotechnology company seeking to develop screening tests for pre-eclampsia. Maarten Postma has received grants and honoraria from various pharmaceutical companies, including companies interested in the content of this article. Antoinette van Asselt has no conflicts of interest that are relevant to the content of this article.
Author contributions Neily Zakiyah performed the systematic review and was responsible for drafting the first version of the manuscript. Maarten Postma and Philip Baker critically revised the paper. Antoinette van Asselt drafted the final version of the manuscript and also acts as the overall guarantor.

Open Access This article is distributed under the terms of the Creative Commons Attribution-NonCommercial 4.0 International License (http://creativecommons.org/licenses/by-nc/4.0/), which permits any noncommercial use, distribution, and reproduction in any medium, provided you give appropriate credit to the original author(s) and the source, provide a link to the Creative Commons license, and indicate if changes were made.

\section{References}

1. Hutcheon JA, Lisonkova S, Joseph KS. Epidemiology of preeclampsia and the other hypertensive disorders of pregnancy. Best Pract Res Clin Obstet Gynaecol. 2011;25(4):391-403.

2. Say L, Chou D, Gemmill A, Tuncalp O, Moller AB, Daniels J, et al. Global causes of maternal death: a WHO systematic analysis. Lancet Glob Health. 2014;2(6):e323-33.

3. Ngoc NT, Merialdi M, Abdel-Aleem H, Carroli G, Purwar M, Zavaleta $\mathrm{N}$, et al. Causes of stillbirths and early neonatal deaths: data from 7993 pregnancies in six developing countries. Bull World Health Organ. 2006;84(9):699-705.

4. National Advisory Body. Confidential enquiry into stillbirths and deaths in infancy report: 1998-1999. 8th Annual Maternal and Child Health Research Consortium. http://www.dhsspsni.gov.uk/ cesdi_report.pdf. 2001.

5. Hyde C, Thornton S. Does screening for pre-eclampsia make sense? BJOG. 2013;120(10):1168-70.

6. North RA, McCowan LM, Dekker GA, Poston L, Chan EH, Stewart AW, et al. Clinical risk prediction for pre-eclampsia in nulliparous women: development of model in international prospective cohort. BMJ. 2011;7(342):d1875.

7. Audibert F, Boucoiran I, An N, Aleksandrov N, Delvin E, Bujold E, et al. Screening for preeclampsia using first-trimester serum markers and uterine artery Doppler in nulliparous women. Am J Obstet Gynecol. 2010;203(4):383.e1-8.

8. Poon LC, Maiz N, Valencia C, Plasencia W, Nicolaides KH. First-trimester maternal serum pregnancy-associated plasma protein-A and pre-eclampsia. Ultrasound Obstet Gynecol. 2009;33(1):23-33.

9. Spencer K, Cowans NJ, Nicolaides KH. Low levels of maternal serum PAPP-A in the first trimester and the risk of pre-eclampsia. Prenat Diagn. 2008;28(1):7-10.

10. Gonen R, Shahar R, Grimpel YI, Chefetz I, Sammar M, Meiri H, et al. Placental protein 13 as an early marker for pre-eclampsia: a prospective longitudinal study. BJOG. 2008;115(12):1465-72.

11. Romero R, Kusanovic JP, Than NG, Erez O, Gotsch F, Espinoza $\mathrm{J}$, et al. First-trimester maternal serum PP13 in the risk assessment for preeclampsia. Am J Obstet Gynecol. 2008;199(2): 122.e1-11.

12. Baumann MU, Bersinger NA, Mohaupt MG, Raio L, Gerber S, Surbek DV. First-trimester serum levels of soluble endoglin and soluble fms-like tyrosine kinase- 1 as first-trimester markers for late-onset preeclampsia. Am J Obstet Gynecol. 2008;199(3): 266.e1-6.

13. Kleinrouweler CE, Wiegerinck MM, Ris-Stalpers C, Bossuyt PM, van der Post JA, von Dadelszen P, et al. Accuracy of circulating placental growth factor, vascular endothelial growth factor, soluble fms-like tyrosine kinase 1 and soluble endoglin in the 
prediction of pre-eclampsia: a systematic review and meta-analysis. BJOG. 2012;119(7):778-87.

14. Kenny LC, Black MA, Poston L, Taylor R, Myers JE, Baker PN, et al. Early pregnancy prediction of preeclampsia in nulliparous women, combining clinical risk and biomarkers: the Screening for Pregnancy Endpoints (SCOPE) international cohort study. Hypertension. 2014;64(3):644-52.

15. Odibo AO, Goetzinger KR, Odibo L, Cahill AG, Macones GA, Nelson DM, et al. First-trimester prediction of preeclampsia using metabolomic biomarkers: a discovery phase study. Prenat Diagn. 2011;31(10):990-4.

16. Kenny LC, Broadhurst DI, Dunn W, Brown M, North RA, McCowan L, et al. Robust early pregnancy prediction of later preeclampsia using metabolomic biomarkers. Hypertension. 2010;56(4):741-9.

17. American College of Obstetricians and Gynecologists. Task Force on Hypertension in Pregnancy. Hypertension in pregnancy. Report of the American College of Obstetricians and Gynecologists' Task Force on Hypertension in Pregnancy. Obstet Gynecol. 2013;122(5):1122-31.

18. World Health Organization. WHO recommendations for prevention and treatment of pre-eclampsia and eclampsia. 2011; Available at: http://whqlibdoc.who.int/publications/2011/97892 41548335_eng.pdf. Accessed Apr 12015.

19. Walter E, Zehetmayr S. Guidelines for health-economic evaluations in Austria. Wien Med Wochenschr. 2006;156(23-24): 628-32.

20. Drummond MF, Jefferson TO. Guidelines for authors and peer reviewers of economic submissions to the BMJ. The BMJ Economic Evaluation Working Party. BMJ. 1996;313(7052):275-83.

21. Drummond MF, Sculpher MJ, Torrance GW, O'Brien BJ, Stoddart GL. Methods for the economic evaluation of health care programmes. 3rd ed. Oxford: Oxford University Press; 2005.

22. Mauskopf JA, Sullivan SD, Annemans L, Caro J, Mullins CD, Nuijten M, et al. Principles of good practice for budget impact analysis: report of the ISPOR Task Force on Good Research Practices-Budget Impact Analysis. Value Health. 2007;10(5): 336-47.

23. World Bank. PPP conversion factor, GDP (LCU per international \$). Available at: http://data.worldbank.org/indicator/PA.NUS. PPP?page=2. Accessed Dec 182013.

24. Husereau D, Drummond M, Petrou S, Carswell C, Moher D, Greenberg D, et al. Consolidated Health Economic Evaluation Reporting Standards (CHEERS) statement. BMJ. 2013;25(346): f1049.

25. Hadker N, Garg S, Costanzo C, Miller JD, Foster T, van der Helm $\mathrm{W}$, et al. Financial impact of a novel pre-eclampsia diagnostic test versus standard practice: a decision-analytic modeling analysis from a UK healthcare payer perspective. J Med Econ. 2010;13(4):728-37.

26. Meads CA, Cnossen JS, Meher S, Juarez-Garcia A, ter Riet G, Duley L, et al. Methods of prediction and prevention of preeclampsia: systematic reviews of accuracy and effectiveness literature with economic modelling. Health Technol Assess. 2008;12(6):iii-iv, 1-270.

27. Shmueli A, Meiri H, Gonen R. Economic assessment of screening for pre-eclampsia. Prenat Diagn. 2012;32(1):29-38.

28. Simon J, Gray A, Duley L. Magpie Trial Collaborative Group. Cost-effectiveness of prophylactic magnesium sulphate for 9996 women with pre-eclampsia from 33 countries: economic evaluation of the Magpie trial. BJOG. 2006;113(2):144-51.

29. Vijgen SM, Koopmans CM, Opmeer BC, Groen H, Bijlenga D, Aarnoudse JG, et al. An economic analysis of induction of labour and expectant monitoring in women with gestational hypertension or pre-eclampsia at term (HYPITAT trial). BJOG. 2010;117(13):1577-85.
30. Blackwell SC, Tomnlinson MW, Berman S, Redman ME, Hassan SS, Berry SM, et al. The use of magnesium sulfate to prevent seizures in the pre-eclamptic gravida: a cost-effectiveness analysis. Prenat Neonatal Med. 2001;6:310.

31. Akolekar R, Syngelaki A, Sarquis R, Zvanca M, Nicolaides KH. Prediction of early, intermediate and late pre-eclampsia from maternal factors, biophysical and biochemical markers at 11-13 weeks. Prenat Diagn. 2011;31(1):66-74.

32. Walker JJ. Pre-eclampsia. Lancet. 2000;356(9237):1260-5.

33. Clark SL, Belfort MA, Dildy GA, Herbst MA, Meyers JA, Hankins GD. Maternal death in the 21st century: causes, prevention, and relationship to cesarean delivery. Am J Obstet Gynecol. 2008;199(1):36.e1-5 discussion 91-2. e7-11.

34. World Health Organization International Collaborative Study of Hypertensive Disorders of Pregnancy. Geographic variation in the incidence of hypertension in pregnancy. Am J Obstet Gynecol. 1988;158(1):80-3.

35. Caro JJ, Briggs AH, Siebert U, Kuntz KM, ISPOR-SMDM Modeling Good Research Practices Task Force. Modeling good research practices-overview: a report of the ISPOR-SMDM Modeling Good Research Practices Task Force-1. Value Health. 2012;15(6):796-803.

36. Verlohren S, Galindo A, Schlembach D, Zeisler H, Herraiz I, Moertl MG, et al. An automated method for the determination of the sFlt-1/PIGF ratio in the assessment of preeclampsia. Am J Obstet Gynecol. 2010;202(2):161.e1-11.

37. Koopmans CM, Bijlenga D, Groen H, Vijgen SM, Aarnoudse JG, Bekedam DJ, et al. Induction of labour versus expectant monitoring for gestational hypertension or mild pre-eclampsia after 36 weeks' gestation (HYPITAT): a multicentre, open-label randomised controlled trial. Lancet. 2009;374(9694):979-88.

38. Visser GH. Obstetric care in the Netherlands: relic or example? J Obstet Gynaecol Can. 2012;34(10):971-5.

39. Altman D, Carroli G, Duley L, Farrell B, Moodley J, Neilson J, et al. Do women with pre-eclampsia, and their babies, benefit from magnesium sulphate? The Magpie trial: a randomised placebo-controlled trial. Lancet. 2002;359(9321):1877-90.

40. Gold M, Siegel J, Russell L, Weinstein M, editors. Cost-effectiveness in health and medicine. 1st ed. Oxford: Oxford University Press; 1996.

41. National Institute for Health and Care Excellence. Hypertension in pregnancy: the management of hypertensive disorders during pregnancy. 2010; Available at: http://www.nice.org.uk/ guidance/cg 107/chapter/1-recommendations\#reducing-the-riskof-hypertensive-disorders-in-pregnancy. Accessed Apr 12015.

42. Park F, Russo K, Williams P, Pelosi M, Puddephatt R, Walter M, et al. Prediction and prevention of early onset pre-eclampsia: the impact of aspirin after first trimester screening. Ultrasound Obstet Gynecol. 2015. Epub 2015 Feb 11.

43. Godfrey KM, Inskip HM, Hanson MA. The long-term effects of prenatal development on growth and metabolism. Semin Reprod Med. 2011;29(3):257-65.

44. Geelhoed JJ, Fraser A, Tilling K, Benfield L, Davey Smith G, Sattar N, et al. Preeclampsia and gestational hypertension are associated with childhood blood pressure independently of family adiposity measures: the Avon Longitudinal Study of Parents and Children. Circulation. 2010;122(12):1192-9.

45. Boney CM, Verma A, Tucker R, Vohr BR. Metabolic syndrome in childhood: association with birth weight, maternal obesity, and gestational diabetes mellitus. Pediatrics. 2005;115(3):e290-6.

46. Kajantie E, Eriksson JG, Osmond C, Thornburg K, Barker DJ. Pre-eclampsia is associated with increased risk of stroke in the adult offspring: the Helsinki Birth Cohort Study. Stroke. 2009;40(4):1176-80.

47. Parkinson JR, Hyde MJ, Gale C, Santhakumaran S, Modi N. Preterm birth and the metabolic syndrome in adult life: a 
systematic review and meta-analysis. Pediatrics. 2013;131(4): e1240-63.

48. Washburn L, Nixon P, Russell G, Snively BM, O'Shea TM. Adiposity in adolescent offspring born prematurely to mothers with preeclampsia. J Pediatr. 2013;162(5):912-7.

49. EURO-PERISTAT. European perinatal health report. 2013; Available at: http://www.europeristat.com/reports.html. Accessed Dec 2014

50. Finucane MM, Stevens GA, Cowan MJ, Danaei G, Lin JK, Paciorek CJ, et al. National, regional, and global trends in bodymass index since 1980: systematic analysis of health examination surveys and epidemiological studies with 960 country-years and 9.1 million participants. Lancet. 2011;377(9765):557-67.

51. Wang YC, McPherson K, Marsh T, Gortmaker SL, Brown M. Health and economic burden of the projected obesity trends in the USA and the UK. Lancet. 2011;378(9793):815-25.
52. Hanson M, Gluckman P. Developmental origins of noncommunicable disease: population and public health implications. Am J Clin Nutr. 2011;94(6 Suppl):1754S-8S.

53. Gordon FK, Ferguson EL, Toafa V, Henry TE, Goulding A, Grant AM, et al. High levels of childhood obesity observed among 3- to 7-year-old New Zealand Pacific children is a public health concern. J Nutr. 2003;133(11):3456-60.

54. May AL, Kuklina EV, Yoon PW. Prevalence of cardiovascular disease risk factors among US adolescents, 1999-2008. Pediatrics. 2012;129(6):1035-41.

55. World Health Organization. Maternal health. 2013; Available at: http://www.who.int/topics/maternal_health/en/. Accessed Dec 2014.

56. United Nations. United Nations millennium development goals and beyond 2015. 2013; Available at: http://www.un.org/ millenniumgoals/maternal. Accessed Dec 2014. 